intelligence. I can find no definition in his paper. He suggests that information transmission needs energy, the human cannot create energy, so the human cannot create information! Pask states, "a human being does not so much respond to stimuli as interpret certain states of his environment as posing problems which he makes an attempt to solve". Is matter not atomic because this book moves entire, then?

Walter contrasts the hardware and software of the machine with the "wetware" of the brain. Ashby considers the coordination of a task organized in sub-groups. Beer suggests improved methods of organization of state and industry. As George states, in industry, "relevancy is the essence". Mays raises the old "can machines think?" problem. Foster seems to suggest that cybernetics demonstrates the existence of life after death. Malic elaborates on the theme of entropy consumed by life. Klir discusses general systems theory, but agrees with Boulding that "all we can say about practically everything is almost nothing".

Muses gives some interesting mathematics. But is this really cybernetics? Helvey has produced an interesting educational syllabus for cybernetics. Using plenty of italics, Challier describes cybernetics as the "science of sciences and the safeguard of man"! The printed paper by Sister Stella Mary makes it all the more tragic that, apparently, she was not allowed to attend the conference. Jones presents a useful collection of examples of positive feedback in nature. Like most of the workers in his particular section of the field of cybernetics, Kvitanishli gives us no practical details of his perceptron networks. Kogan concludes, very truly, that there are more questions than answers when considering brain organization.

Perhaps the above very short selection gives some idea of the variety of the papers presented at the conference. The papers mentioned above have all been from the Main Papers and from the section on "The Meaning of Cybernetics". The number of papers printed is 105 , and they even include two which take the form of discussion and criticism of works of art. Clearly, Wiener's unfortunate definition of cybernetics can be twisted to cover almost any topic.

Those of us who attended the conference have only now been able to read the complete set of papers. Looking back, I feel that it is a great pity that it was not possible to prepare preprints of the papers. With so many simultaneous sessions, it was difficult, if not impossible, to select meetings for attendance.

The organizers certainly did a good job, but are not large international meetings such as this better organized by the existing national learned societies, who have secretariats especially for such functions? It is possible also that fewer irrelevant papers might then be accepted and published. JOHN F. YOUNG

\section{An Aspect of Virology}

Medical Virology. By Frank Fenner and David O. White. Pp. xviii +390 . (Academic: New York and London, October 1970.) $£ 4.45$.

A NOTABLE lack felt by professional virologists and virology students alike is a succinct, reliable and comprehensive textbook. Excellent reference books, monographs and symposia are available to cover a wide range of different fields within the general area of virology, but a really good textbook of manageable length is hard to find.

It is a pleasure, therefore, to welcome Fenner and White's Medical Virology which provides not only such a textbook but also extensive reference coverage within the large field designated by its title and in related neighbouring fields as well. This is achieved by devoting well over half the book to an admirable survey of the principles and techniques of virology in general, and keeping the smaller second part of the book for a consideration of individual families of human viruses. Each chapter in Part I provides a masterly review of a topic vital to an understanding of virology. The style is clear and simple, extremely complex problems are made readily comprehensible and in areas of doubt a synthesis of the controversial points of view seems always somehow to be followed by a firm word of guidance from the authors. It is hard to envisage a better balanced or more useful introductory textbook for a complicated subject. To make the chapters even more valuable, each is followed by a recapitulation summary and a list giving guidance for further reading.

Despite the risk of writing a rave notice, I am still filled with wonder on reflecting on the seeming ease with which extremely complicated topics like viral genetics, virus multiplication or the effects of viruses on cells have, in the space of $10-15$ pages, been reduced to an orderly survey of the basic facts involved, together with suitable explanations of their significance. It is also a pleasure to note that the diagrams and illustrations, whether photomicrographs or electron micrographs, are of an extremely high quality, well chosen and highly relevant to the points they seek to illustrate. This book can be used, therefore, both as an introductory textbook and as a very reliable and solid reference book with which to start out on a quest for information on some specialized field in animal virology.

With regard to Part II, systematized surveys or catalogues, whether it be in plant nomenclature, bacterial classification, or the listing and describing of viruses, tend, by their very nature, to be boring. Once again, Fenner and White's new book scores a minor triumph; this section, too, by virtue of the engaging and direct style of the authors, remains readable and extremely interesting throughout. All in all, this book is to be highly recommended to students and established workers alike. It will for long be a "must" on the shelves of all those connected, however remotely, with virological topics, and it should be stressed that despite its title it is not in the least limited to material likely to be of interest only to medical workers. The basic scientist, the research diagnostician, the physician and the epidemiologist will, together with many others, find that an outstanding textbook in this field has now been provided.

M. A. Epstein

\section{Red Cells and White}

Regulation of Hematopoiesis. Edited by Albert S. Gordon. Vol. 1: Red Cell Production. Pp. xviii $+1-766+9$. Vol. 2: White Cell and Platelet Production. Pp. xviii + 767-1658. (Appleton-CenturyCrofts: New York, August 1970.) Two volumes: $\$ 78.50$.

THE scope of these books reflects the development of haematology from the study of clinical material, entirely for medical purposes, to an important branch of experimental biology. Studies of haematopoiesis at the tissue, cellular, and molecular levels continue to make fundamental contributions to developmental and molecular biology, in particular those areas concerned with cellular regulatory systems, and may provide insights of increasing value to clinicians in preventing or controlling a variety of haematopoietic disorders.

In the first volume, comparative haematology is introduced by a detailed study of insect haemocytopoiesis and a brief commentary on haematopoietic mechanisms in non-mammalian vertebrates. Haematopoietic regulation is placed in the context of an organized tissue by articles on bone marrow and spleen histophysiology. Various aspects of the haematopoietic stem cell, control and kinetics of its differentiation, and tissue interactions in vivo and in vitro, are usefully reviewed in five chapters. Ultrastructural and kinetic aspects of erythropoiesis are supplemented by chapters on kinetic models and general application of control theory to red cell differentiation. Preparation and chemistry of erythro- 